\title{
Early child development: a challenge in China
}

\author{
Jie Shao ${ }^{1}$ \\ Received: 15 November 2018 / Accepted: 20 November 2018 / Published online: 10 January 2019 \\ (c) Children's Hospital, Zhejiang University School of Medicine 2019
}

Early childhood development has been linked with adult health and wellbeing. It is a necessary component of the sustainable development goals (SDGs) [1, 2], which are conceptualized from a lifespan perspective. Neuroscience researches in the past two decades have elucidated that the period from conception through early childhood (i.e., at least the first 3 years) is foundational for brain development [3]. Children acquire an orderly progression of skills that form the blueprint for subsequent development. Epigenetic, immunological, physiological, and psychological adaptations to the environment occur during this period, and these adaptations affect development throughout the life course [4]. Risks including poverty, stunting, and nutritional deficiencies contribute to inequities in children's development [5], resulting in over 200 million children under 5 years of age in low- and middle-income countries not reaching their developmental potential, leading to an average deficit of $19.8 \%$ in adult annual income [3]. Quality interventions in the early years of children have long-term beneficial effects with cost efficiency, including reductions in violence [6], depression and social inhibition, improving adult health, competence (e.g., learning and academic attainment), and subsequently economic productivity $[7,8]$.

Therefore, investments in early childhood, most importantly in the first 3 years of age, have strong economic and social justification; appropriate nurturing care through health, nutrition, responsive parenting, safety and security, and early learning should be provided for children to reach their potential and obtain optimal development.

China has the largest populations of children under five. The Chinese Government has attached great importance in the early childhood development. In 1992, the "Planning Outline of Child Development in China in the 1990s" was issued by the State Council of China, which was the first

Jie Shao

shaojie@zju.edu.cn

1 Children's Hospital, Zhejiang University School of Medicine, Hangzhou, China national action plan for children to achieve their developmental potential, followed by the "Outline of Child Development in China (2001-2010)" and the "Outline of Child Development in China (2011-2020)", which present national goals and strategies of 10-year plan for early child development across health, education, child protection, environment and social protection sectors.

During the past two decades, the conditions and services for the survival, protection and development of early childhood in China have been significantly improved. The number of children exposed to stunting or extreme poverty declined by $40 \%$ from 2004 to 2010 [9]. The mortality rate of newborns, infants and children under 5 years of age fell from $22.8 \%$ o $32.2 \%$ and $39.7 \%$ in 2000 to $4.5 \%$ o $6.8 \%$ and $9.1 \%$ in 2017 , respectively. The vaccination rate included in the national immunization program has reached more than $90 \%$. Though with remarkable improvements in advocating early childhood development in China, big challenges remain to be daunting.

The major challenges in early childhood development in China are the great disparities among the populations with different social-economical level. 2017 China Children Development Reports revealed that there are very prominent issues regarding the development of children in poor rural areas of China: (1) the absolutely large number of children exposed to poverty, with a population of 40 million children and 20 million aged 0-6 years; (2) poor care giving; (3) the obvious inequality in healthcare access; (4) deprivation of early learning stimulation or preschool education; (5) the remarkable psychological problems; and (6) the incomplete welfare and protection of children [10].

According to the Report on the Status of Nutrition and Chronic Diseases of Chinese Residents (2015) [11], stunting, underweight and anemia were major nutritional problems for children aged 0-6 years in poor rural areas of China [11]. The rates of stunting (19.0\%), underweight (5.1\%) and anemia (16.6\%) in poor rural areas were about four to five times of that in urban areas and one to two times of that in other rural areas in 2013 [11]. Also, micronutrition deficiencies such as zinc, and vitamin $\mathrm{A}$ and $\mathrm{D}$ deficiencies in young 
children were still very common in the poor rural areas. The rates of zinc deficiency and vitamin A deficiency were as high as $50 \%$ and $23.8 \%$, respectively, in children aged 0-6 years in those areas, and the prevalence of vitamin A deficiency was around 6.3-folds of their peers in urban areas. The prevalence of anemia in children aged 6-24 months was $26.3 \%$ (2.4\% of them are moderate anemia) in those poor rural areas [12].

The migrant population and left-behind children are at the most risk for early childhood development. According to National Bureau of Statistics in 2010, the number of children from migrant family aged 0-5 years and rural left-behind children in China was 9 million and 23.42 million, respectively, accounting for $9.97 \%$ and $25.95 \%$ of the total number of children aged 0-5 years. Due to poor living conditions and low-education level of caregivers, high percentage of migrant children and left-behind children have different levels of malnutrition. In addition, children in poor rural areas face severe challenges in early parenting and preschool education. Many parents migrate to work in the large cities, and leave their children in the care of grandparents with little cognitive stimulation in the crucial first years of life. As a result, around 29\% infants aged 6-12 months in rural Shanxi Province were scored below normal on the Bayley test, nearly twice the $15 \%$ of babies falling at the low end in any population. About a third of students $(31 \%)$ in poor rural areas dropped out of junior high school [13]. Gao et al. also found that children with both parental labor migration had 1.95, 1.57, 1.67, 1.61 and 1.39 times risk of getting potential delay in communication, gross motor, fine motor problem solving and overall development delay, respectively. Parental migration for work may negatively influence the early physical, psychological and behavioral developments during early life [14].

In all, nutrition in young children from poor rural areas has become the most important issue to be solved first in China. For improving the nutritional status of children in poor rural areas, several early interventions have been carried out. In 2008, a full-fat soy powder mixed with multiple micronutrient powders (Ying Yang Bao, YYB) was developed in China [15]. YYB can be given to infants and young children aged 6-24 months as home fortification for complementary feeding through national intervention projects in poor rural counties, such as "Improving Children's Nutrition in Poor Rural Regions" project conducted by the Government of China in 2012. The project has covered more than 4 million infants aged 6-24 months in 341 counties among 21 provinces in western and middle regions by the end of 2015 [15]. Data show that YYB have enhanced the growth of infants with respect to both anthropometry and cognition, decreased anemia and stunting prevalence in infants from $49.5 \%$ to around $23.6 \%$, and from $10.1 \%$ to $8.4 \%$, respectively $[16,17]$. This nutrition intervention program in China presents an example for developing countries aiming to improve nutrition in early life. Then, the "China-UNICEF Integrated Early Child Development (IECD) in Poor Rural Regions" project was launched by the Government of China under the support from the United Nations Children's Fund (UNICEF) in 2013. The interventions targeting the five key components of nurturing care (i.e., child and caregiver health, child nutrition, early learning support, child protection and social security) were delivered through the IECD program to children aged $0-35$ months and their caregivers, which effectively improved the mental health of caregivers, optimized families' child feeding and early learning behaviors, and reduced caregivers' violent disciplines in the poverty-stricken rural China [18]. In 2015, the concept of Early Childhood Development was advocated nationwide as a national strategy. A total of 50 National Early Childhood Development Demonstration bases have been established at maternal and children's hospitals in the health care system between 2015 and 2018. Multisectoral services and interventions for early childhood development are also delivered in the bases, such as maternal and prenatal health care and nutritional management during pregnancy, newborn asphyxia resuscitation program, Kangaroo Mother Care for small infants, breastfeeding and complementary feeding promotion, education and support, prevention and treatment of iron deficiency and malnutrition, child physical and developmental monitoring and screening, and responsive caregiving and positive parenting education. Those services expanded its vision of health beyond prevention and treatment of diseases to play their important part in supporting families to deliver nurturing care and facilitate early childhood development.

Though a tremendous gap existing between the richest and poorest populations presented with the inequality status of young children's social-emotional development and positive parenting score, the nationally representative data from the China Family Panel Survey showed that the trends of inequalities have experienced improvement between 2010 and 2014 [19]. The SDGs call for equitable opportunities for children everywhere to achieve their full potential. All those issues and the apocalyptic gaps between different populations in rural and urban China are both a challenge and an opportunity for advocating early childhood development. It is important for us to make tailored policies and programs by a life-course approach and cost-efficiency way, deliver early childhood development services with a greater integration of the pediatric healthcare services with other sectors, such as education and child protection, and increase investment targeting the most vulnerable children to help achieve SDGs in China. 
Author contributions SJ drafted and revised the manuscript, and approved the final version of the manuscript.

Funding This study was supported by the Natural Science Foundation of China (81773440).

\section{Compliance with ethical standards}

Ethical approval Not needed.

Conflict of interest The author has no financial relationships relevant to this article to disclose.

\section{References}

1. United Nations. Transforming our world: the 2030 agenda for sustainable development. Version 1, September 2015. Geneva: United Nations; 2015.

2. Richter LM, Daelmans B, Lombardi J, Heymann J, Boo FL, Behrman JR, et al. Investing in the foundation of sustainable development: pathways to scale up for early childhood development. Lancet. 2017;389:103-18.

3. Lake A, Chan M. Putting science into practice for early child development. Lancet. 2015;385:1816-7.

4. Hanson JL, Nacewicz BM, Sutterer MJ, Cayo AA, Schaefer SM, Rudolph KD, et al. Behavioral problems after early life stress: contributions of the hippocampus and amygdala. Biol Psychiatry. 2015;77:314-23.

5. Walker SP, Wachs TD, Gardner JM, Lozoff B, Wasserman GA, Pollitt E, et al. Child development: risk factors for adverse outcomes in developing countries. Lancet. 2007;369:145-57.

6. Walker SP, Chang SM, Vera-Hernández M, Grantham-McGregor S. Early childhood stimulation benefits adult competence and reduces violent behavior. Pediatrics. 2011;127:849-57.

7. Shonkoff JP, Garner AS, Committee on Psychosocial Aspects of Child and Family Health, Committee on Early Childhood, Adoption, and Dependent Care, Section on Developmental and Behavioral Pediatrics. The lifelong effects of early childhood adversity and toxic stress. Pediatrics. 2012;129:e232-46.

8. Gertler P, Heckman J, Pinto R, Zanolini A, Vermeersch C, Walker $\mathrm{S}$, et al. Labor market returns to an early childhood stimulation intervention in Jamaica. Science. 2014;344:998-1001.
9. Lu C, Black MM, Richter LM. Risk of poor development in young children in low-income and middle-income countries: an estimation and analysis at the global, regional, and country level. Lancet Glob Health. 2016;4:e916-22.

10. China Development Research Foundation. China children development reports. 2017. http://www.cdrf.org.cn/jjh/pdf/fazhanbaog ao.pdf. Accessed 1 Nov 2018.

11. National Health and family Planning Commission of the People's Republich of China, Bureau of Diseases Prevention and Control. Report on the status of nutrition and chronic diseases of Chineses residents. Beijing: People's Medical Publishing House; 2016 (in Chinese).

12. Children's Department of All-China Women's Federation, Maternal and Child Health Service Division of the National Health and Family Planning Commission. Nutrition and family upbringing of 0-6 year old children in poor areas of China. 2015. http://www. ccppg.com.cn/kuaibao/shehui/2015-06-23/151918.html. Accessed 1 Nov 2018.

13. Normile D. China's childhood experiment. Science. 2017;357:1226-30.

14. Gao YJ, Zhao CX, Zhang JX, Wang XL. The influence of parents going out to work on the early development of left-behind children aged 0-3 years old. Chin J Reprod Health. 2018;29:301-6 (in Chinese).

15. Ying HY, Bao Y. Improving complementary feeding for Chinese infants in poor regions. Nestle Nutr Inst Workshop Ser. 2017;87:131-8.

16. Sun J, Dai Y, Zhang S, Huang J, Yang Z, Huo J, et al. Implementation of a programme to market a complementary food supplement (Ying Yang Bao) and impacts on anaemia and feeding practices in Shanxi, China. Matern Child Nutr. 2011;7(Suppl 3):96-111.

17. Huo J, Sun J, Fang Z, Chang S, Zhao L, Fu P, Wang J, et al. Effect of home-based complementary food fortification on prevalence of anemia among infants and young children aged 6 to 23 months in poor rural regions of China. Food Nutr Bull. 2015;36:405-14.

18. Shi HF, Zhang JX, Wang XL, Xu YY, Dong SL, Zhao CX, et al. Effectiveness of integrated early childhood development intervention on nurturing care for children aged 0-35 months in rural China. Zhonghua Er Ke Za Zhi. 2018;56:110-5 (in Chinese).

19. Li Z, Jiang Y, Li M, Lu C. Inequalities in socio-emotional development and positive parenting during childhood: evidence from China 2010-2014. SSM Popul Health. 2018;5:8-16. 